\title{
Severe summer rainfall in China associated with enhanced global warming
}

\author{
Dao-Yi Gong ${ }^{1, *}$, Shao-Wu Wang ${ }^{2}$ \\ ${ }^{1}$ Key Laboratory for Environmental Change and Natural Disaster Research, China Ministry of Education, \\ Institute of Resources Science, Beijing Normal University, 100875 Beijing, China \\ ${ }^{2}$ Department of Geophysics, Peking University, 100871 Beijing, China
}

\begin{abstract}
Trends of extreme wet and dry conditions during recent decades were examined using observed data for eastern China. Mean precipitation for the region has shown a significant downward trend from the 1950s to the mid-1970s, and a positive trend since the late 1970s. The change in trend since the late 1970 s, i.e. the period during which enhanced global warming emerged, is most prominent. The linear trend of the mean summer rainfall anomalies over the 4 subregions studied was $+7.5 \%$ decade $^{-1}$. Changes in the trend of severe wet and dry events are not symmetrical. During the period 1977-1998, the number of severe wet stations increased at the rate of 20.3 decade $^{-1}$, but the trend for severe dry events was only -5.4 decade $^{-1}$. Similar rainfall changes can be found over many global land areas. The summer rainfall in eastern China showed only a negligible secular trend during the period 1880-1998. However, the decadal variations were clear. The mean rainfall in 1990-1998 was higher than for any other decade in the last $100 \mathrm{yr}$. The linear trend of the 33-station mean during 1977-1998 was $+47.5 \mathrm{~mm}$ decade $^{-1}$; such a strong increase is unprecedented in the record since 1880. Decadal variations and global warming may both play important roles in the recent significant increase in summer rainfall. This paper also presents the results of greenhouse and/or aerosol forcing experiments, in which summer precipitation over eastern China is generally estimated to rise. There are many uncertainties, however, in the regional precipitation simulations. For example, the modeled rainfall is sensitive to whether aerosols are included or not. Further research is needed to determine whether there is a substantial relationship between the rainfall changes in China and global greenhouse warming.
\end{abstract}

KEY WORDS: Severe summer rainfall $\cdot$ Global warming $\cdot$ China

\section{INTRODUCTION}

The possible changes in global land precipitation associated with global warming over the 20th Century have been paid more attention recently (Hulme 1996, Nicholls et al. 1996, Hulme et al. 1998). It is now widely recognized that changes in the number, frequency or intensity of extreme climate events are likely to have a much greater impact on natural and human systems than a small shift in the mean values (Katz \& Brown 1992). In particular, the possible changes in extreme rainfall events are highlighted. For example, Karl et al.

*E-mail: gdy@pku.edu.cn
(1995) and Karl \& Knight (1998) analyzed the trends in the percentage of total seasonal and annual precipitation occurring for heavy daily rainfall events over the USA. A significant positive trend in percentage rainfall falling in heavy events was evident in the USA, largely due to a strong increase in extreme rainfall events in summer. Investigations in some other regions have also been undertaken (Yu \& Neil 1991). Numerical model simulations of the climatic effects of enhanced greenhouse effects also suggest that the frequency and intensity of some extreme events may change (McGuffie et al. 1999).

Flooding is one of the most serious disasters that commonly occurs in China. The Chinese have suffered 
a lot from extremely severe flooding caused by exceptionally heavy rainfalls during the last 2 decades. For example, the remarkable floods that occurred in quick succession in 1980, 1991, 1996 and 1998 caused considerable damage and loss of life. The extreme rainfall events in China are attracting increased attention (Zhai et al. 1999). At the same time, the eastern Asia continent is one of the areas showing the strongest warming trend in the world during the last 2 decades (Gong \& Wang 1999a, Wang \& Gong 2000). Some questions frequently posed are: Are there links between global warming and the flooding in China? Have the changes in severe rainfall events occurred already? Will floods become more frequent and/or more severe in the 21st Century due to the enhanced greenhouse effect?

In this paper we demonstrate the low frequency trends in rainfall and extreme rainfall conditions and investigate the possibility of a connection between global warming and rainfall trends for China during the last few decades. We will also examine the severe summer rainfall changes simulated by HadCM2 simulations in the domain of eastern Asia and compare these to observations.

Eastern China (east of $\sim 100^{\circ} \mathrm{E}$ ) is China's wettest region. Summer is the rainy season. The summer monsoon brings plenty of rainfall over these regions, and accounts for about $40-50 \%$ and $60-70 \%$ of the annual precipitation in the south and north of China respectively (China Meteorological Administration 1994). Therefore in this paper we will only analyze the summer rainfall over eastern China.

\section{OBSERVED CHANGES IN EXTREME SUMMER RAINFALL}

Precipitation is very variable between regions within China. For example, some authors indicated there might be a negative relationship for summer rainfall between the middle-eastern China and the vicinities on an annual time scale. It is reasonable to define several different climatological regions. Following most Chinese climate scientists, 4 regions in eastern China are defined as shown in Fig. 1. Region A approximately covers the Pearl River valley, and Regions B and $\mathrm{C}$ roughly cover most of the Changjiang River valley and the Yellow River valley respectively. There are frequent droughts and floods in these regions.

The monthly precipitation data of the 160 stations used in this study were supplied by the National Climate Center of China. The large modern network of weather observing stations in China has been in operation since 1951. For complete homogeneity, as some data are missing during 1951-1953, only the records since 1954 are used for the analysis. All monthly precipitation data were recalculated in terms of anomalies in percent with respect to 1961-1990.

Besides seasonal mean precipitation, we define here 2 other kinds of indices to measure the extent of the severe summer rainfall events. One is the number of severe dry stations in summer, and the other is the number of severe wet stations in summer. These 2 objective indices are defined as the total number of stations with a summer (June, July and August) monthly rainfall anomaly of below $-50 \%$ and above $+50 \%$ respectively. This criteria matches about 15 to $20 \%$ probability of the 1 -tailed test.

Previous studies have shown that the global mean precipitation and global land mean precipitation have positive sensitivity to global temperature variations (Nicholls et al. 1996, Hulme et al. 1998). Given that the influence of planetary scale warming on regional scale precipitation may be non-linear and very complicated, it is very difficult to tell exactly how much of the variability of rainfall results from global warming. We think that detecting the changes in trends may be a simple but acceptable choice. The Mann-Kendall test (Sneyers 1990) was applied to test the significance of trends in summer temperature and rainfall. For temperature there are significant negative trends from 1954 to 1976 and positive trends from 1977 to 1998.

It is very interesting to note that the recent change in the summer rainfall in eastern China is consistent to some degree with the hemispheric temperature trends. The mean precipitation of eastern China has a significant negative trend from the 1950s to the mid-1970s and a positive trend since the late 1970s. Of the 4 individual regions, there are 3 in which the summer rain-

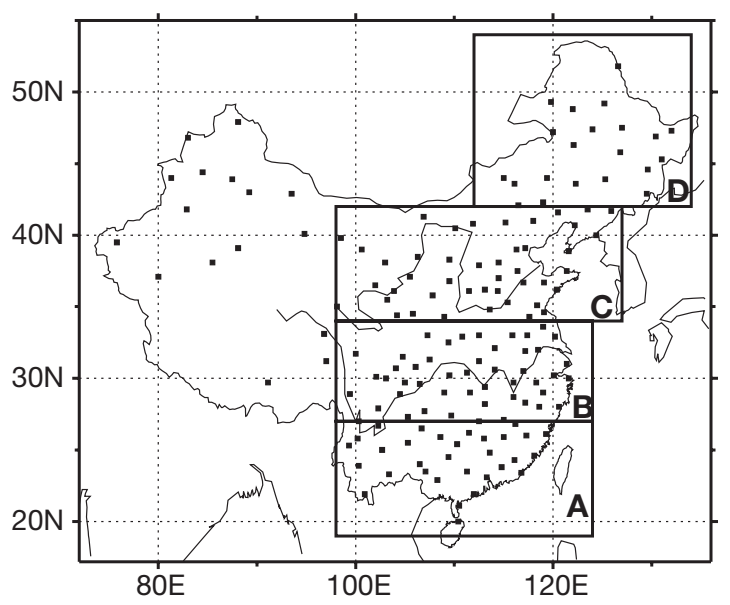

Fig. 1. Definition of the 4 regions over eastern China. (घ) Stations for which monthly precipitation data are available. The variability of summer rainfall among these regions is relatively independent 
Table 1. Precipitation and severe summer rainfall statistics. Significance: ${ }^{* * *} 99 \%,{ }^{* *} 95 \%,{ }^{*} 90 \%$

\begin{tabular}{|c|c|c|c|c|c|c|c|c|c|c|}
\hline \multirow[t]{2}{*}{ Region } & \multirow[t]{2}{*}{$\begin{array}{l}\text { Number of } \\
\text { stations }\end{array}$} & \multicolumn{3}{|c|}{$\begin{array}{l}\text { Linear trend of the } \\
\text { numbers of severe wet } \\
\text { stations (no. decade }{ }^{-1} \text { ) }\end{array}$} & \multicolumn{3}{|c|}{$\begin{array}{l}\text { Linear trend of the } \\
\text { numbers of severe dry } \\
\text { stations (no. decade }{ }^{-1} \text { ) }\end{array}$} & \multicolumn{3}{|c|}{$\begin{array}{c}\text { Linear trend of the } \\
\text { rainfall } \\
\left(\% \text { decade }^{-1}\right)\end{array}$} \\
\hline & & $1954-76$ & $1977-98$ & $1954-98$ & $1954-76$ & $1977-98$ & $1954-98$ & $1954-76$ & $1977-98$ & $1954-98$ \\
\hline A & 31 & +1.0 & $+8.3^{* * *}$ & +0.9 & $-2.4^{*}$ & -1.2 & 0.0 & +3.1 & $+14.6^{* *}$ & +1.6 \\
\hline B & 48 & $-9.0^{* * *}$ & $+7.8^{* *}$ & +0.1 & 1.9 & -2.3 & $-1.9^{*}$ & $-9.1^{* *}$ & $+9.5^{* *}$ & +0.9 \\
\hline $\mathrm{C}$ & 44 & -3.7 & +2.8 & -0.2 & 3.9 & -0.3 & -0.2 & -6.8 & +2.2 & -1.3 \\
\hline $\mathrm{D}$ & 21 & $-2.7^{* *}$ & $+2.2^{*}$ & +0.5 & 0.5 & -2.1 & -0.5 & $-6.7^{*}$ & $+6.8^{*}$ & +1.3 \\
\hline All & 144 & $-14.4^{* * *}$ & $+20.3^{* * *}$ & +1.3 & 3.9 & -5.4 & -2.5 & -5.4 & $+7.5^{* * *}$ & +0.5 \\
\hline \multicolumn{4}{|c|}{$\begin{array}{l}\text { Trends of the northern hemisphere } \\
\text { summer temperature }\end{array}$} & $\begin{array}{l}1954-76 \\
1977-98 \\
1954-98\end{array}$ & \multicolumn{3}{|c|}{$\begin{array}{r}-0.087^{\circ} \mathrm{C} \text { decade } \mathrm{e}^{-1 * *} \\
0.269^{\circ} \mathrm{C} \text { decade } \mathrm{dec}^{-1 * * *} \\
0.087^{\circ} \mathrm{C} \text { decade } \mathrm{e}^{-1 * * *}\end{array}$} & & & \\
\hline
\end{tabular}

fall declined when northern hemispheric temperature cooled from the 1950s to the mid-1970s (see Table 1). The only exception is Region A, which is located at much lower latitudes. It is interesting to note that some other regions at similar latitudes (e.g. the southern US) also show wetter trends during the same period (see Fig. 4).

Fig. 2 shows time series of numbers of extreme summer rainfall events. The linear trends for the 2 periods 1954-1976 and 1977-1998 are displayed as dotted lines. The years 1976-1978 are shaded to emphasize the possible connection with the summer mean northern hemispheric temperature showing contrary trends for the 2 periods, as shown in Fig. 3. This figure shows that the severe wet rainfall events change significantly when the global temperature increases or declines, but that changes in severe dry events are not as significant as those of wet events. This implies that more floods could occur in China associated with the warming periods, but at the same time, the risk of drought may not significantly decrease. Associated with the observed enhanced global warming since the late 1970s, rainfall increases distinctly in all 4 regions. The linear trend of mean summer rainfall anomalies over Regions A to $\mathrm{D}$ is $+7.5 \%$ decade $^{-1}$, significant at the $99 \%$ confidence level. The trend for mean summer northern hemispheric temperature in the same period is $+0.23^{\circ} \mathrm{C}$ decade $^{-1}$, also significant at the $99 \%$ level. The correlation coefficient between the mean rainfall over Region A to D and the hemispheric temperature for the period from 1954-1998 is 0.27 . This result is generally consistent with the widely accepted proposition that enhanced global warming will intensify the global hydrological cycle and bring more summer rainfall.

The features of severe rainfall that often result in extreme floods and droughts are highlighted. Usually, when there is more rainfall, conditions with increased probabilities of severe wet events and decreased prob- abilities of severe dry events are expected. However, it is of most interest to note that there are significantly different features between the severe wet and severe dry rainfall events during the latter decades. Although the numbers of the severe wet stations since the late 1970s has increased at the rate of 20.3 decade $^{-1}$, which is significant at the $99 \%$ confidence level, the trend for the severe dry events is not as strong as expected, only -5.4 decade $^{-1}$, which is not significant. These characteristics are true for all 4 regions as shown in Table 1. It is clear that changes in severe wet and severe dry events are not symmetrical. Zhai et al. (1999) recently reported that the annual mean precipitation intensity (i.e. annual precipitation/rainy days) in China has increased significantly since the late 1970s, which means more rain fell in a shorter time period, bringing higher risk of both drought and flood. Whether the extreme heavy rainfall is more sensitive to temperature changes, however, needs further examination.

Regarding the consistency of China's summer rainfall with northern hemisphere temperature as mentioned previously, one may naturally query whether similar behavior can be seen in other regions.

Summer precipitation trends over northern hemispheric land were calculated from 1954 to 1976 and from 1977 to 1998 . The gridded precipitation data set used here was constructed and provided by Hulme (1992). As shown in Fig. 4, the wetter trend during the period 1977-1998 does not only occur over eastern China, but also over central Asia, the western US and Canada and other regions. During the period 1954-1976, the most significant drier trends appear over eastern and central Asia, western Europe, northern Africa and other regions. Many regions show opposite trends during the 2 periods similar to China. Statistics show grid box numbers with wetter trends are greater in number than those with drier trends during a warming period, whilst more grid boxes with drier trends can be expected during the cooling period. 

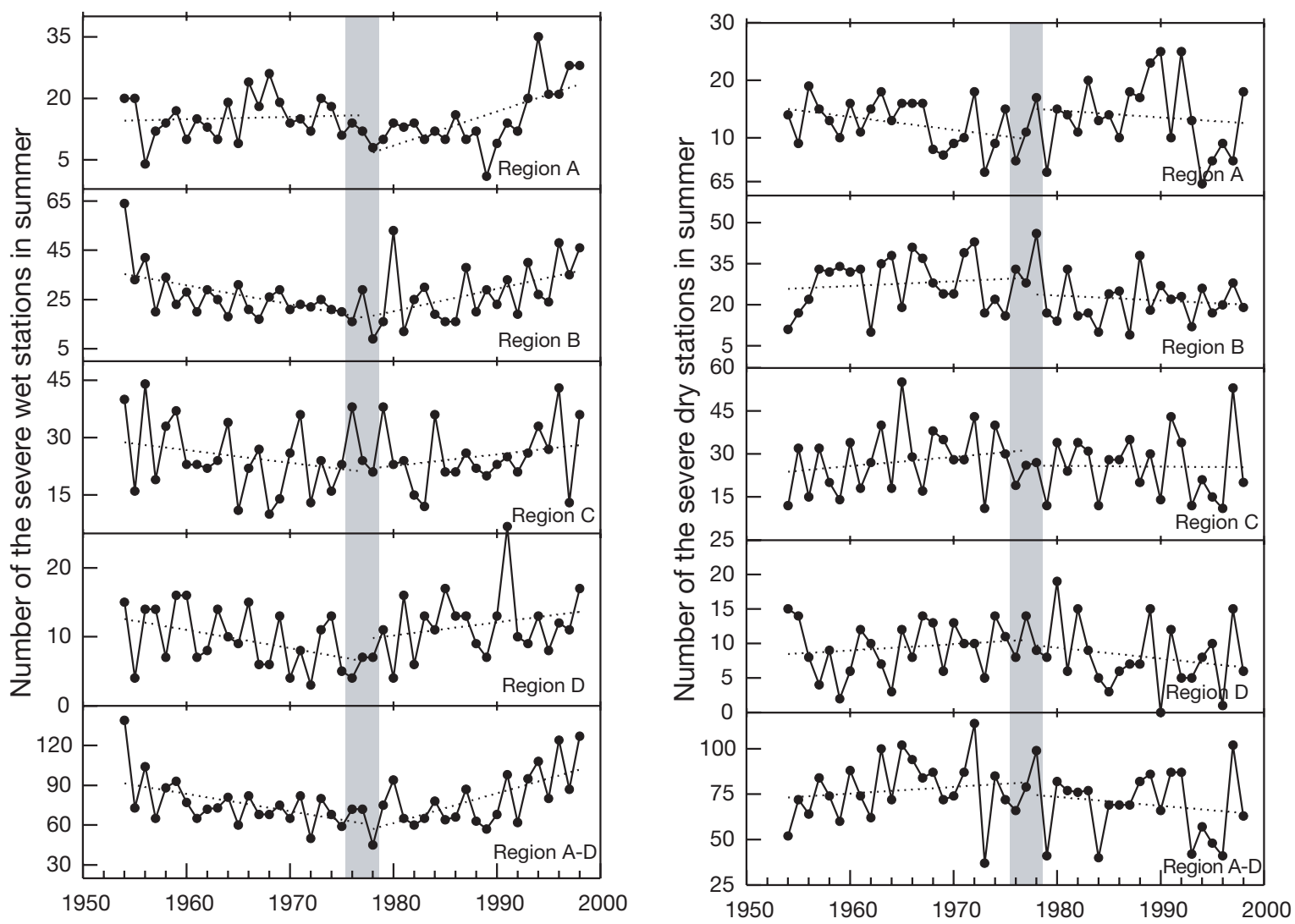

Fig. 2. Time series of the numbers of extreme summer rainfall events. Dotted lines: the linear trends for the 2 periods of $1954-1976$ and 1977-1998. Please note the ordinates are drawn on different scale. The change in trends around 1976-1978 is shaded in all panels. Northern hemisphere mean temperature data were obtained from the Climate Research Unit, University of East Anglia, UK (www.cru.uea.ac.uk/cru/data/temperat.htm)

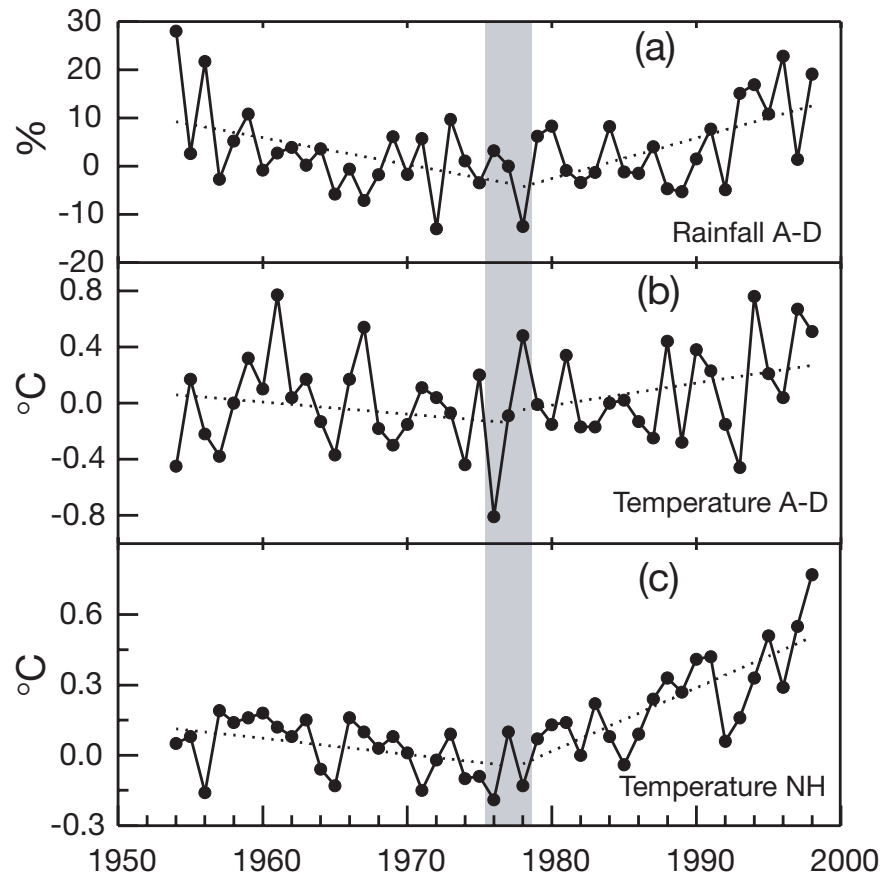

For example, $58.8 \%$ of the grid boxes showed a positive trend and $41.2 \%$ showed a negative trend during the period 1977-1998 (Fig. 5). However, $43.4 \%$ of the grid boxes showed a positive trend and $56.6 \%$ showed a negative trend during the period 1954-1976.

Dai et al. (1998) analyzed severe dry and wet conditions over the globe and found that from 1900-1995 there are small secular trends over many land areas while large multi-year to decadal variations in the moisture condition are common. The unique low-frequency changes in moisture condition since the mid1970s are thought mainly to result from the frequent El Niño events and global warming. Investigation of the long-term variations in summer rainfall in China is necessary and helpful for us to clarify whether the recent upward trend is unusual. Unfortunately, there

Fig. 3. Mean values of (a) rainfall and (b) temperature over eastern China and (c) northern hemisphere temperature in summer. Dotted lines: the linear trends for the periods 1954-1976 and 1977-1998 
a) $1977-98$

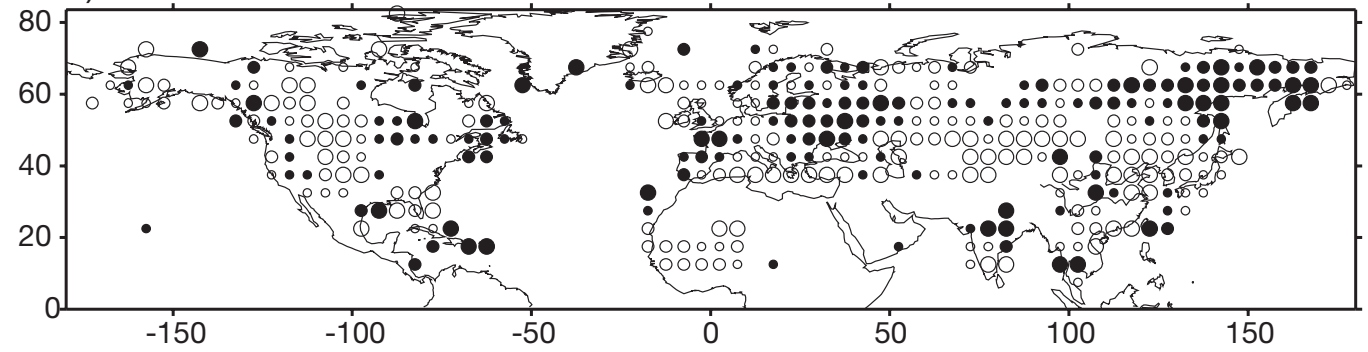

b) $1954-76$

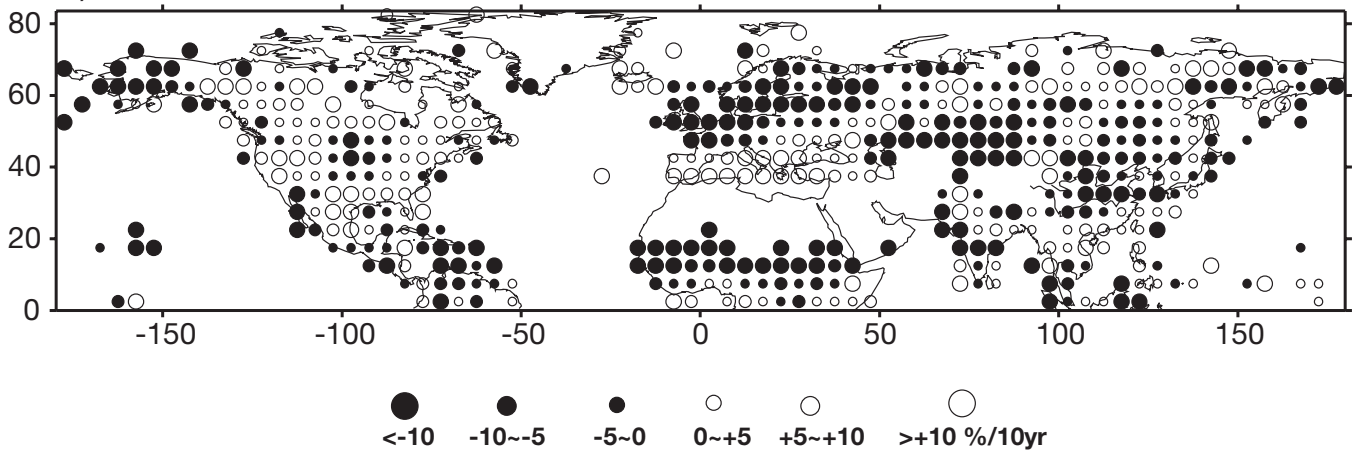

Fig. 4. Trends in summer precipitation (JJA) over the northern hemisphere during (a) 1977-1998 and (b) 1954-1976

are not enough long observational records. Wang et al. (2000) recently published a seasonal precipitation time series for 33 stations in mainland China since 1880. All the stations are located east of $105^{\circ} \mathrm{E}$. Averaged summer rainfall anomalies of the 33 stations are shown in Fig. 6. Similar to many global land areas, the summer rainfall in eastern China shows a negligible secular trend. The linear trend of the whole period 1880-1998 was only -1.4 mm century ${ }^{-1}$. However, the decadal variations are clear; the rainfall is less during the 1890 s to 1900 s and 1970 s to 1980 s. Some wet periods include the 1880s, 1910s, 1940s and 1990s. The increase in summer rainfall during the most recent decade is especially prominent. The mean rainfall of 1990-1998 is higher than for any other decade in the record since 1880. The linear trend of the 33-station mean during 1977-1998 was $+47.5 \mathrm{~mm}$ decade $^{-1}$ (significant at the $99 \%$ confidence level). The other comparable 20-yr period is 1900-1920, during which the trend was $41.9 \mathrm{~mm}$ decade $^{-1}$ (significant at the $90 \%$ confidence level). The observed global warming of the past century occurred primarily in 2 distinct periods, one is from the 1920s to the 1940s and the other from the late 1970 s to the present. The strong wetter trend that occurred during 1900-1920 is not consistent with the early global warming. The decadal variation of the summer rainfall maybe play important role. However, the strong upward trend that has emerged during the most recent 2 decades is unprecedented in the record since 1880.

\section{SIMULATION RESULTS}

Most simulations show a significant increase in global average precipitation due to a doubling of $\mathrm{CO}_{2}$ (for example, see the 1990 IPCC report). Can the wetter trend in China be seen in the model climate under the

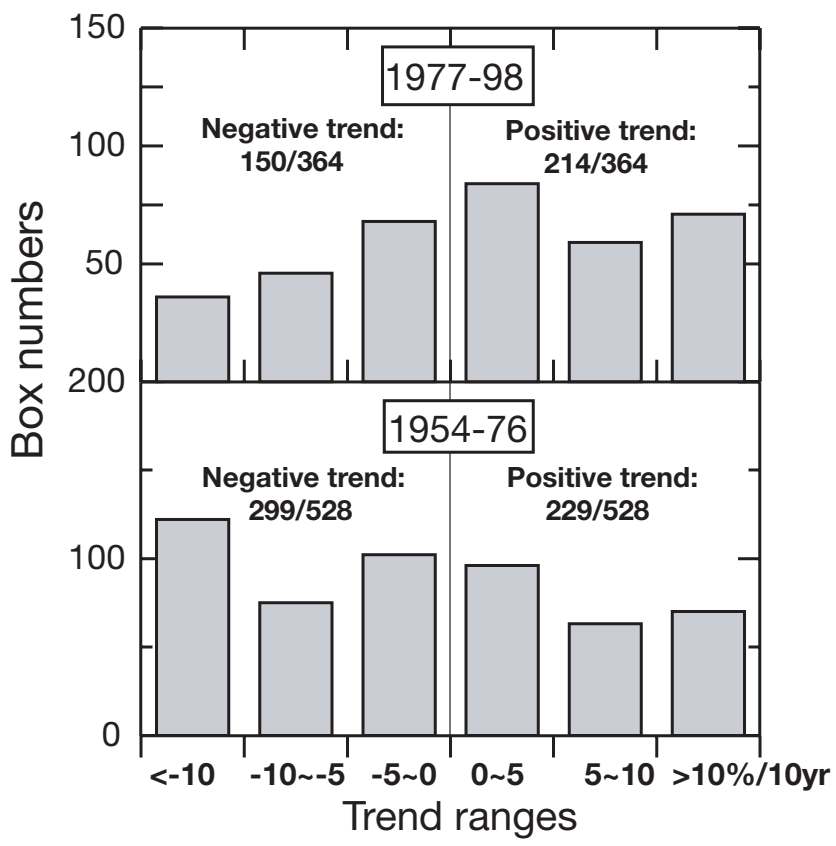

Fig. 5. Numbers of grid boxes within different rainfall trend ranges for the periods 1977-1998 and 1954-1976 


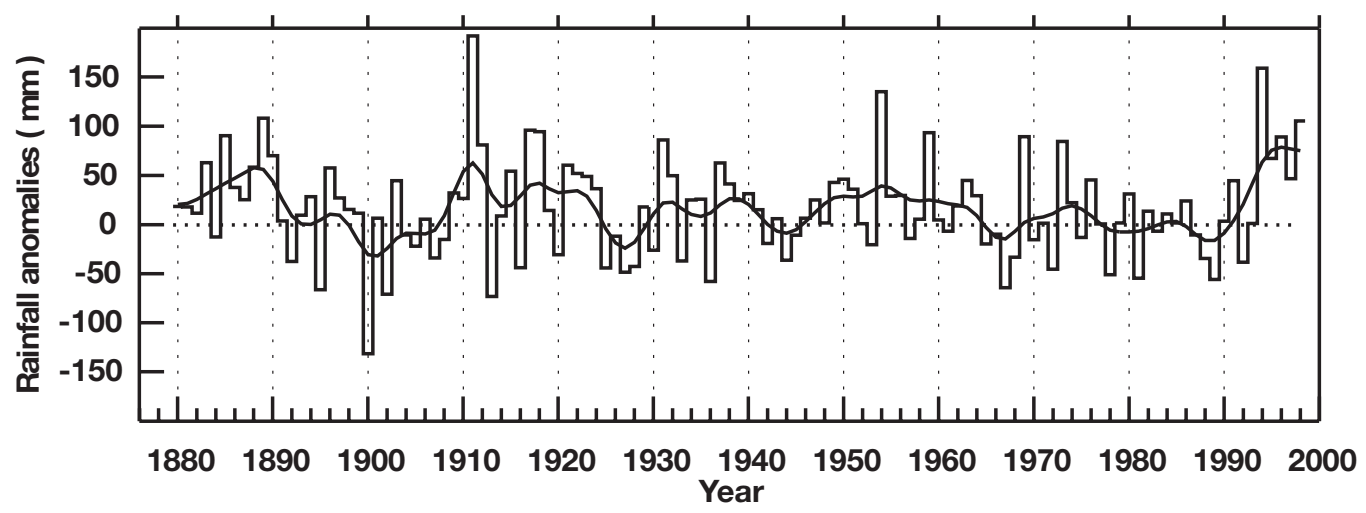

Fig. 6. Mean summer rainfall anomalies of 33 stations in mainland China east of $105^{\circ} \mathrm{E}$ (with respect to 1961-1990)

'imposed warming'? Here data from simulations performed by the Hadley Centre using HadCM2 model (see Mitchell \& Johns 1997 and Johns et al. 1997 for more details) are analyzed. The model simulations extend over the period 1860-2100. The 2 sets of forcing use observed greenhouse gas only forcing (HadCM2 GG) and combined greenhouse gas and sulphate aerosol forcing (HadCM2 GS) for the period 1860-1990, and then a post-1990 forcing scenario of the IS92a emissions scenario of the IPCC. Many analyses are undertaken based on these simulated data, for example, Hulme et al. (1998) reported the global-mean precipitation sensitivity over $1900-1996$ is between 1.82 (GG) or 1.86 (GS) $\%{ }^{\circ} \mathrm{C}^{-1}$ of global warming. In this study, we analyzed the HadCM2 results over the domain of eastern Asia for the period 1954-1998, the same period as the observed data. The

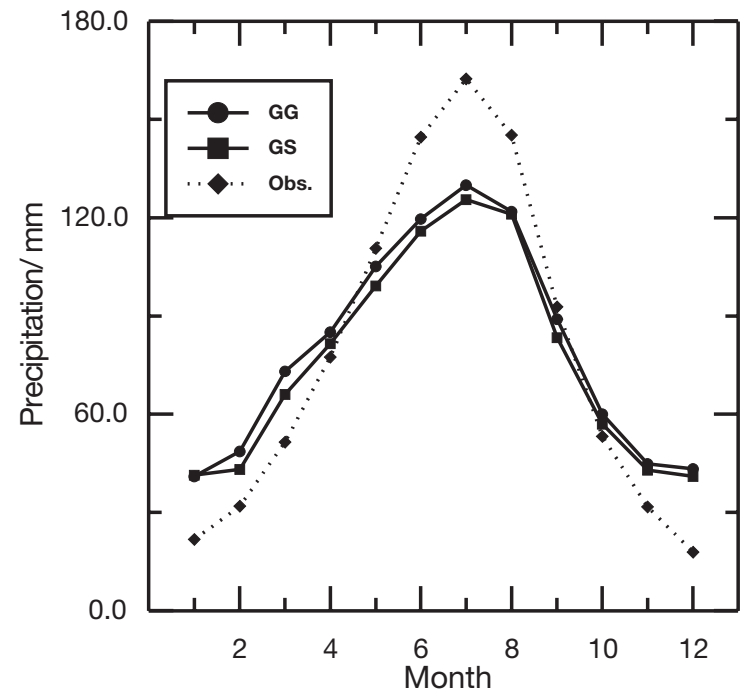

Fig. 7. Seasonal cycle of precipitation over eastern China for simulated and observed data (1954-1998). Simulation conducted with HadCM2; forcings: greehouse gas only (GG) and greenhouse gas and sulphate aerosol (GS) model resolution was $2.5^{\circ}$ latitude $\times 3.75^{\circ}$ longitude; so there were 73 latitude rows and 96 longitude columns (7008 data points in total).

The number of grid boxes located within the 4 regions was less than the number of observation stations. The total grid box number was 81 . The numbers of data points in Regions A, B, C and D were 18, 18, 21 and 24 respectively. To increase the stability of analysis, we use the model data of the 81 grid boxes as a whole to examine the rainfall variability induced by the greenhouse warming. We use 2 similar indices for analysis. One is the number of severe dry grids in summer, and the other is the number of severe wet grids in summer. These 2 objective indices are also defined as the total numbers of grid boxes with the summer (June, July and August) monthly rainfall anomaly below $-50 \%$ and above $+50 \%$ respectively.

It is essential for the model to capture the seasonality of rainfall over the region. Fig. 7 shows the seasonal cycle of monthly rainfall for both the observations and simulations. Generally, the features of simulated precipitation are consistent with the observed, but the peak in summer rainfall is about $25 \%$ less than that for the observed.

Fig. 8 shows the simulated severe wet and dry rainfall events, the summer mean rainfall and the northern hemispheric mean temperature. The trends for the periods 1954-1976 and 1977-1998 are calculated separately in Table 2 for the purpose of comparison with the observations. The GS and GG temperatures had strong warming trends in both periods. In general, trends in the summer rainfall and severe rainfall events were not as strong as the observations. The numbers of severe wet grid boxes showed a similar general tendency for GG and GS forcing to yield positive trends, especially in the period 1977-1998. The rainfall also had an upward trend, as expected.

The trend of the number of severe dry grid boxes was negative except for the GG forcing in the period 


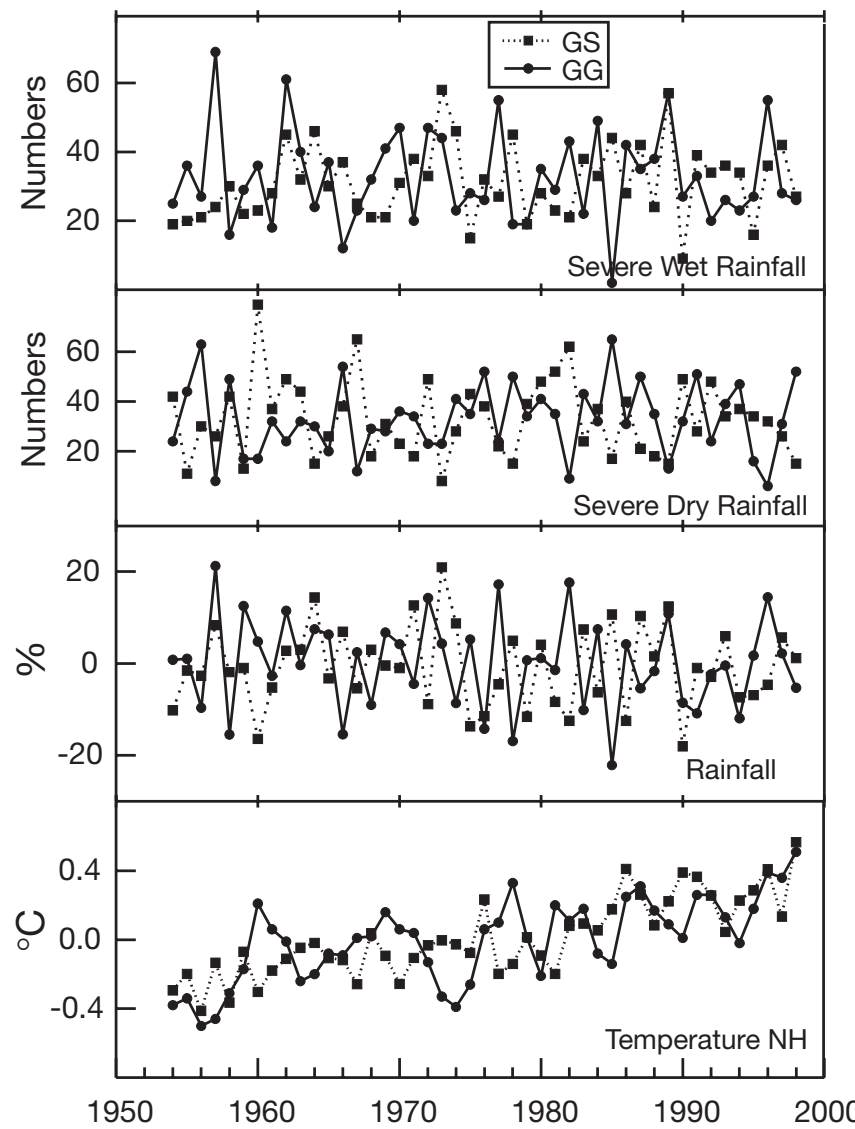

Fig. 8. Simulated climatic changes for the period 1954-1998. Rainfall and severe rainfall events are all calculated for eastern China, i.e. Regions A to D, as a whole. The anomalies of rainfall and the the northern hemispheric mean summer temperature are with reference to the period 1961-1990. For statistics of the trends see Table 2. GG, GS: see Fig. 7

1954-1976. However, the magnitude of the severe dry event trend was stronger than that of severe wet events in the period 1977-1998. For the observed data, severe wet events had a strong and significant upward trend, but the downward trend of the severe dry events was weak and not significant for the period 1977-1998.
This relationship can be explained by a shift in the distribution; when the mean rainfall value becomes greater, the probability of extreme positive events increases and the probability of extreme negative events decreases. These simulated results imply that changes in the mean values may play an important role in the genesis of extreme events associated with global warming in eastern China.

Nevertheless, the wetter trends in simulations may be just coincidence. The greenhouse signal in the model is not very strong in the period up to 1998 and could be swamped by natural variability. The simulation outputs beyond 1998 should be analyzed; this would enable the regional greenhouse signal to be better established. Fig. 9 shows the simulated hemispheric temperature and rainfall over eastern China for the period 2000-2049. Scenarios GG and GS show a much stronger warming trend than in the period 1954-1998. Associated with the significant warming, the summer rainfall over eastern China also shows a significant wetter trend of $+2.8 \%$ decade $^{-1}$ at the $99 \%$ confidence level in the GG results. However, unfortunately, a drier trend of $-1.7 \%$ decade $^{-1}$ appears in the GS run.

The precipitation sensitivity to planetary temperature is normally used to measure the degree of the potential impacts of global warming on rainfall. The sensitivity of eastern China summer rainfall to northern hemispheric temperature changes is summarized in Table 3. During the period 1954-1998, the observed summer rainfall sensitivity was $+8.8 \%{ }^{\circ} \mathrm{C}^{-1}$. Although the positive trends show that wetter conditions can be expected, the simulated sensitivity for the whole period 1954-1998 was -4.5 and $-4.9 \%{ }^{\circ} \mathrm{C}^{-1}$ in GG and GS respectively. This may be caused by the low signal to noise ratio. It is interesting to note that the sensitivities in GG and GS are of opposite sign during the period 2000-2049. Under the relatively lower warming condition of GS, the sensitivity was $-5.5 \%{ }^{\circ} \mathrm{C}^{-1}$, but under the more enhanced warming condition of GG, the sensitivity was $+7.8 \%{ }^{\circ} \mathrm{C}^{-1}$, which is very close to the

Table 2. Simulated linear trends of rainfall for enhanced greenhouse conditions over eastern China for the period 1954-1998. GG, GS: see Fig. 7. Significance: ${ }^{* * *} 99 \%,{ }^{* *} 95 \%,{ }^{*} 90 \%$

\begin{tabular}{|c|c|c|c|c|}
\hline Forcing & $\begin{array}{c}\text { Numbers of severe } \\
\text { wet grids } \\
\text { (no. decade }{ }^{-1} \text { ) }\end{array}$ & $\begin{array}{c}\text { Numbers of severe } \\
\text { dry grids } \\
\text { (no. decade } \text { (n) }^{-1} \text { ) }\end{array}$ & $\begin{array}{l}\text { Rainfall trend } \\
\left(\% \text { decade }{ }^{-1}\right)\end{array}$ & $\begin{array}{c}\text { Northern hemispheric } \\
\text { temperature } \\
\left({ }^{\circ} \mathrm{C} \text { decade }^{-1}\right)\end{array}$ \\
\hline \multicolumn{5}{|c|}{$1954-1976$} \\
\hline GS & $5.09^{*}$ & -2.37 & 1.07 & $0.12^{* *}$ \\
\hline GG & 1.08 & 0.44 & 0.00 & $0.12^{* * *}$ \\
\hline \multicolumn{5}{|c|}{$1977-1998$} \\
\hline GS & 1.78 & -4.96 & 0.66 & $0.14^{* *}$ \\
\hline GG & 2.16 & -4.17 & 1.49 & $0.23^{* * *}$ \\
\hline
\end{tabular}




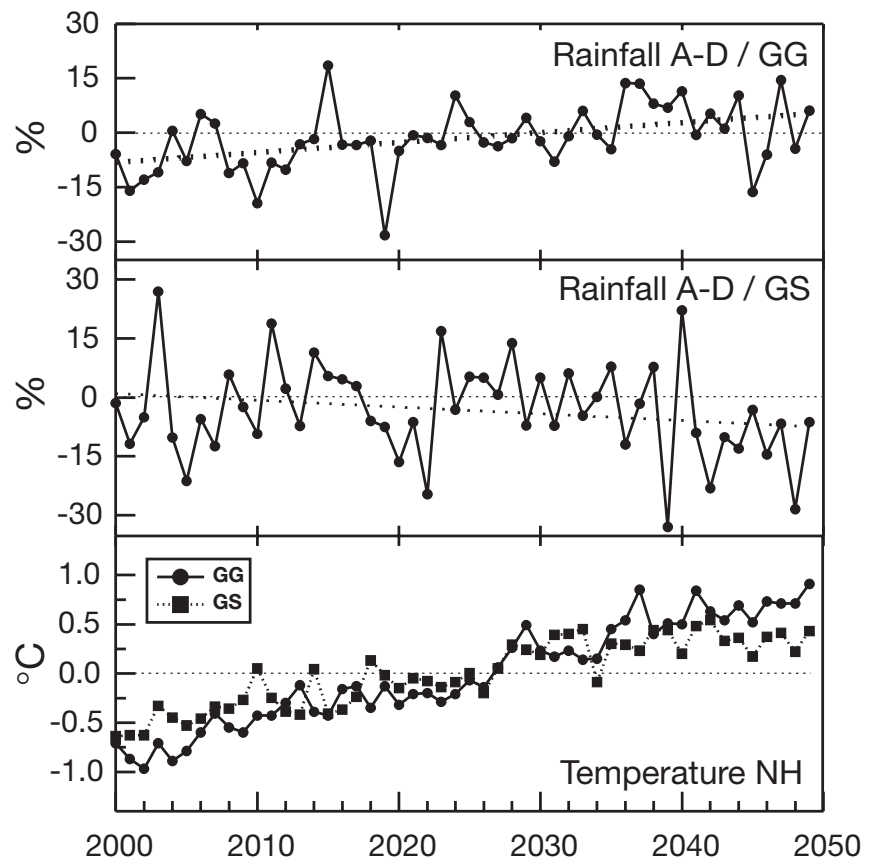

Fig. 9. Simulated northern hemisphere summer temperature and mean precipitation anomalies over eastern China. All with respect to 2000-2049. GG, GS: see Fig. 7

Table 3. Summer rainfall sensitivity to northern hemispheric temperature changes $\left(\%{ }^{\circ} \mathrm{C}^{-1}\right)$. Significance: ${ }^{* * *} 99 \%$

\begin{tabular}{|lccc|}
\hline & & $1954-98$ & $2000-49$ \\
\hline Simulation & GG & -4.5 & $7.8^{* * *}$ \\
& GS & -4.9 & -5.5 \\
Observation & & +8.8 & - \\
\hline
\end{tabular}

observed value of $8.8 \%{ }^{\circ} \mathrm{C}^{-1}$. Hulme et al. (1992) analyzed the results of $7 \mathrm{GCM}$ scenario experiments under double $\mathrm{CO}_{2}$ conditions and found that all 7 runs showed increasing summer precipitation over eastern Asia $\left(70-140^{\circ} \mathrm{E}, 15-60^{\circ} \mathrm{N}\right)$. The summer precipitation sensitivities to global warming vary from +1.8 (Geophysical Fluid Dynamics Laboratory) to $+8.2 \%$ degree $^{-1}$ (Max-Planck-Institut), with an average $+3.8 \%$ degree $^{-1}$.

The difference between the observed and simulated results may be due to 2 possible sources. One possible cause may be the low skills in modeling the internal physical process of precipitation, since the model variance is often lower than the observations. For example, although the simulated temperature trend during the period 1977-1998 under the GG forcing is equal to the observed value of $+2.3^{\circ} \mathrm{C}$ decade $e^{-1}$, the trend of rainfall is only $2.16 \%$ decade $^{-1}$, much lower than the observed value of $7.5 \%$ decade ${ }^{-1}$. The other possible cause may be the internal or external forcing of the real climate system, which could be responsible for the decadal or inter-decadal variability of rainfall and for the high variance of the observations.

There are many obstacles to the simulation of precipitation. Over eastern Asia, the modeling of regional scale precipitation sensitivity to global warming also has many uncertainties (Li et al. 1994, 1995). For example, in earlier GCM experiments presented by Hulme et al. (1994), precipitation was estimated to rise over most of eastern Asia in all seasons; however, the uncertainty range attached to this estimate is much wider. It is hard to tell whether the recently observed wetter trend has been induced by the enhanced greenhouse effect. To estimate the robust regional changes of precipitation, better models and more runs are needed.

\section{DISCUSSION AND CONCLUSION}

It is generally claimed that the increased radiative energy near the surface associated with the enhanced greenhouse effect is partly balanced by increased radiation and latent heat fluxes. IPCC (1990) anticipate an increase in convective rainfall, because the radiative warming of the surface is most likely to result from an increase in the latent heat flux instead of the sensible heat flux. The resulting increase in convective activity could lead to an increase in the frequency and intensity of heavy rainfall (Gordon et al. 1992, McGuffie et al. 1999). However, most of the atmospheric moisture over eastern China is transported by the Asia monsoon, especially the eastern Asia monsoon. The large-scale changes in summer rainfall over eastern China are closely connected with the summer monsoon. For example, the severe droughts in the 1960s covering most of northern China could have been caused mainly by the abrupt weakness of the summer monsoon which began in the mid-1960s (Guo 1981). The possible role that the monsoon plays in changing the severe summer rainfalls of China under the enhanced greenhouse condition remains unquantified

Dai et al. (1998) indicated that since the late 1970s, there have been some increases in the combined percentage of areas of severe drought and severe wet areas. In 1974-1976 the trend of more El Niño conditions in the equatorial Pacific began. The influence of the recent shift in the El Niño/Southern Oscillation (ENSO) on decadal rainfall changes has been investigated. Gaffen \& Barnett (1992) showed that a numerical model driven with observed global sea surface temperatures reproduced the sharp (10 to $20 \%$ ) rise in tropospheric moisture content over the tropics during 
the mid-1970s. Graham (1995) also indicated that there are strong relationships between the recent enhancement of the tropical hydrologic cycle and the increasing tropical ocean temperature. Although it was found that ENSO has a significant influence on the rainfall over China (Gong \& Wang 1999b), the influences in northern and southern China are opposite. During El Niño years, the rainfall conditions over southern China are usually wetter than normal, but over northern China rainfall usually decreases. The most significant impacts appear in autumn and winter. It seems that the trend towards more summer precipitation over eastern China during the last couple of decades has a very weak relationship with ENSO.

Although simulated changes in regional precipitation have many uncertainties and simulations cannot tell exactly to what degree greenhouse warming has impacted the recent rainfall changes in China, the observed changes during the recent decades do show some interesting facts. Especially during the enhanced global warming period of the mid-1970s to the present, the significant increase in rainfall is unprecedented in the record since 1880. The decadal variation and global warming may both play important roles in the recent significant increase in summer rainfall.

Acknowledgements. This research was supported by the National Key Developing Program for Basic Sciences under Grant G1998040900. Model data from the Hadley Center has been supplied by the Climate Impacts LINK Project. We thank Dr D. Viner for making these data available. The global precipitation data was constructed and supplied by Dr Mike Hulme at the Climatic Research Unit, University of East Anglia. We also thank Prof. Zongci Zhao of the National Climate Center of China and Ms Lilia Li of the University of Illinois at Urbana-Champaign for their generous help. We are indebted to 2 anonymous reviewers for constructive comments that were most helpful in improving the paper.

\section{LITERATURE CITED}

China Meteorological Administration (1994) Atlas of climatic resources of China. China Map Press, Beijing

Dai AG, Trenberth KE, Karl TR (1998) Global variations in droughts and wet spells: 1900-1995. Geophys Res Lett 25(17):3367-3370

Gaffen DJ, Barnett TP (1992) A comparison of observations and model simulations of tropospheric water vapor. J Geophys Res 97:2775-2780

Gong DY, Wang SW (1999a) 1998: the warmest year on record in China during the last century. Meteorol Monthly 25(8): 1-4 (in Chinese)

Gong DY, Wang SW (1999b) Impacts of ENSO on rainfall of global land and China. Chin Sci Bull 44(9):852-856

Gordon HB, Whetton PH, Pittock AB, Fowler AM, Haylock MR (1992) Simulated changes in daily rainfall intensity due to the enhanced greenhouse effect: implication for extreme rainfall events. Clim Dyn 8:83-102

Graham NE (1995) Simulation of recent global temperature trends. Science 267:666-671
Guo QY (1981) Summer monsoon and rainfall in China during the last 30 years. Acta Geogr Sin 36:187-195 (in Chinese)

Hulme M (1992) A 1951-80 global land precipitation climatology for the evaluation of General Circulation Models. Clim Dyn 7:57-72

Hulme M (1996) Recent climatic change in the world's dryland. Geophys Res Lett 23(1):61-64

Hulme M, Wigley T, Jiang T, Zhao ZC, Wang FT, Ding YH, Leemans R, Markham A (1992) Greenhouse effect induced climate change and its impact on China. Climatic Research Unit, Norwich/World Wildlife Fund, Glaud/ China Meteorological Administration, Beijing, p 1-57

Hulme M, Zhao ZC, Jiang T (1994) Recent and future climate change in East Asia. Int J Climatol 14:637-658

Hulme M, Osborn TJ, Johns TC (1998) Precipitation sensitivity to global warming: comparison of observations with HadCM2 simulations. Geophys Res Lett 25(17): $3379-3382$

IPCC (1990) Climate change: the IPCC scientific assessment. Cambridge University Press, Cambridge, p 131-172

Johns TC, Carnell RE, Crossley JF, Gregory JM, Mitchell JFB, Senior CA, Tett SFB, Wood RA (1997) The second Hadley Centre coupled ocean-atmosphere GCM: model description, spinup and validation. Clim Dyn 13:103-134

Karl TR, Knight RW (1998) Secular trends of precipitation amount, frequency and intensity in the United States. Bull Am Meteorol Soc 79:233-241

Karl TR, Knight RW, Plummer N (1995) Indices of climate change for the United States. Bull Am Meteorol Soc 77: 279-292

Katz RW, Brown BG (1992) Extreme events in a changing climate: variability is more important than averages. Clim Change 21:289-302

Li XD, Zhao ZC, Wang SW, Ding YH (1994) Evaluation of regional climate change simulation: a case study. IPCC Special Workshop on Article 2 of the United Nations Framework Convention on Climate Change, 17-21 October 1994, Fortaleza, Brazil, p 68-70

Li XD, Zhao ZC, Wang SW, Ding YH (1995) Evaluation of CGCM and simulation of regional climate change in east Asia. Acta Meteorol Sin 9(4):385-401

McGuffie K, Henderson-Sellers A, Holbrook N, Kothavala Z, Balachova O, Hoekstra J (1999) Assessing simulations of daily temperature and precipitation variability with global climate models for present and enhanced greenhouse climate. Int J Climatol 19(1):1-26

Mitchell JFB, Johns TC (1997) On the modification of the global warming by sulphate aerosols. J Clim 10:245-267

Nicholls N, Gruza GV, Jouzel J, Karl TR, Ogallo LA, Parker DE (1996) Observed climate variability and change. In: Houghton JT et al. (eds) Climate change 1995: the science of climate change. Cambridge University Press, Cambridge, p 133-192

Sneyers R (1990) On statistical analysis of series of observations. World Meterological Organization Tech Note No. 143, WMO No. 415, WMO, Geneva

Wang SW, Gong DY (2000) Enhancement of the warming trend in China. Geophys Res Lett 27(16):2581-2584

Wang SW, Gong DY, Ye JL, Chen ZH (2000) Long-term seasonal precipitation series in eastern China. Acta Geogr Sin 55(3):281-293 (in Chinese)

Yu B, Neil DT (1991) Global warming and regional rainfall: the difference between averaged and high intensity rainfalls. Int J Climatol 11:653-661

Zhai PM, Ren FM, Zhang Q (1999) Detection of trends in China's precipitation extremes. Acta Meteorol Sin 57(2): 208-216 (in Chinese) 